
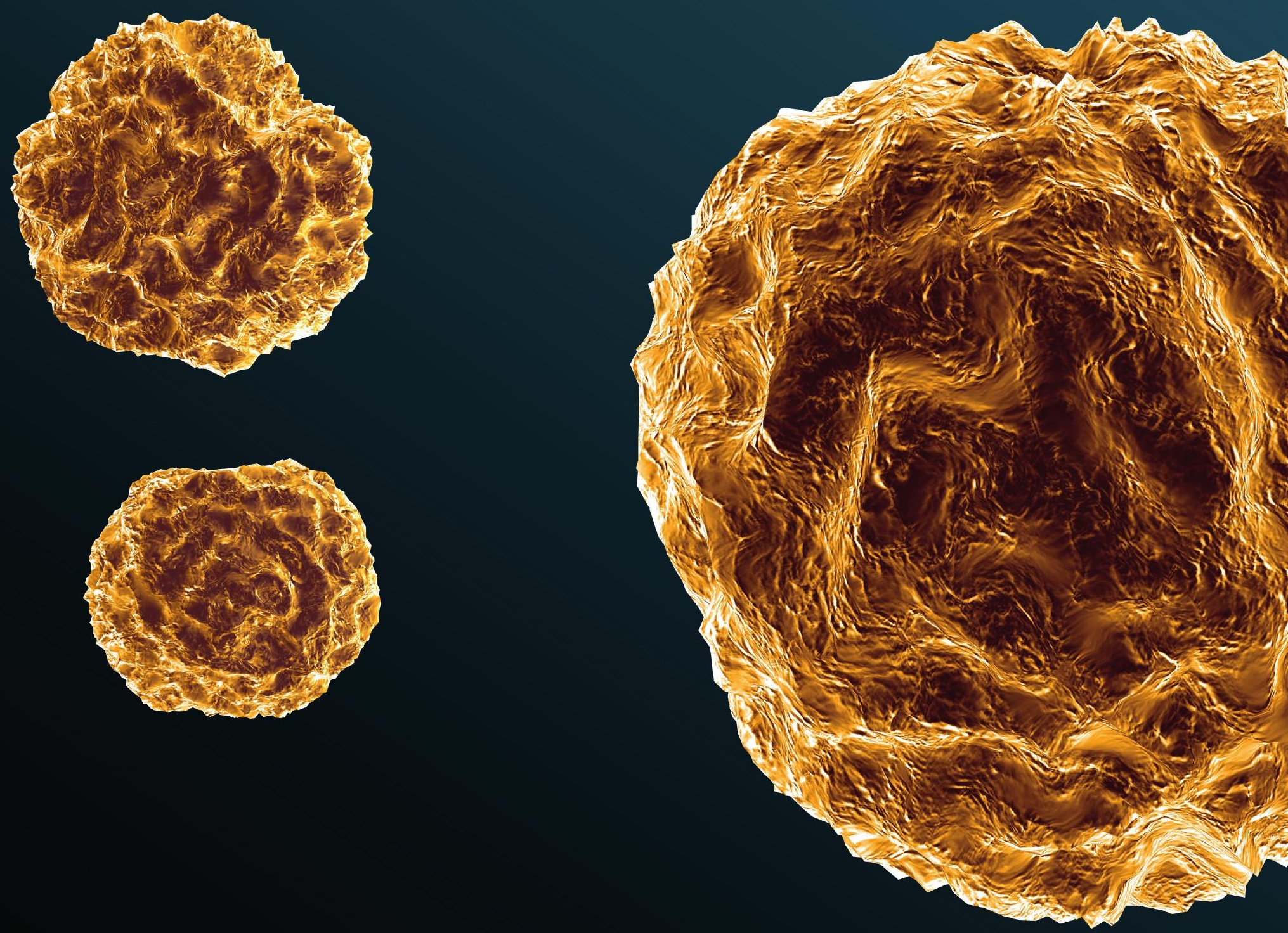

\title{
Evaluatie van de forfaitaire waarden voor totaal fosfor in mestcode 41 en 42
}





\section{Evaluatie van de forfaitaire waarden voor totaal fosfor in mestcode 41 en 42}

P.J.L. Derikx en B. van de Kooi

Dit onderzoek is uitgevoerd door Wageningen Food Safety Research, instituut binnen de rechtspersoon Stichting Wageningen Research en in opdracht van en gesubsidieerd door NVWA onder contractnummer 20333172. 
Derikx, P.J.L., B. van de Kooi, 2021. Evaluatie van de forfaitaire waarden voor totaal fosfor in mestcode 41 en 42. Wageningen, Wageningen Food Safety Research, WFSR-rapport 2021.016. 12 blz.; 0 fig.; 1 tab.; 4 ref.

Projectnummer: 1207392801

Projecttitel: Evaluatie van de forfaitaire waarden voor totaal fosfor en stikstof in mestcode 41 en 42 Projectleider: P.J.L. Derikx

Dit rapport is gratis te downloaden op https://doi.org/10.18174/554478 of op http://www.wur.nl/food-safety-research (onder WFSR publicaties).

(C) 2021 Wageningen Food Safety Research, instituut binnen de rechtspersoon Stichting Wageningen Research. Hierna te noemen WFSR.

Het is de opdrachtgever toegestaan dit rapport integraal openbaar te maken en ter inzage te geven aan derden. Zonder voorafgaande schriftelijke toestemming van het WFSR is het niet toegestaan:

a. dit door WFSR uitgebrachte rapport gedeeltelijk te publiceren of op andere wijze gedeeltelijk openbaar te maken;

b. dit door WFSR uitgebrachte rapport, c.q. de naam van het rapport of WFSR, geheel of gedeeltelijk te doen gebruiken ten behoeve van het instellen van claims, voor het voeren van gerechtelijke procedures, voor reclame of antireclame en ten behoeve van werving in meer algemene zin;

c. de naam van WFSR te gebruiken in andere zin dan als auteur van dit rapport.

Postbus 230, 6700 AE Wageningen, T 03174802 56, E info.wfsr@wur.nl, www.wur.nl/food-safetyresearch. WFSR is onderdeel van Wageningen University \& Research.

WFSR aanvaardt geen aansprakelijkheid voor eventuele schade voortvloeiend uit het gebruik van de resultaten van dit onderzoek of de toepassing van de adviezen.

WFSR-rapport 2021.016

Verzendlijst:

- J. Noordsij, LNV

- P. Suyker, NVWA 


\section{Inhoud}

Samenvatting

1

Algemeen

7

Methode

8

Resultaat \& discussie

9

Conclusie en aanbevelingen

10

Literatuur

11 



\section{Samenvatting}

Sinds januari 2019 zijn de forfaitaire fosfaatgehaltes voor varkensgier en filtraat na mestscheiding, respectievelijk mestcode 42 en 41 mestcode aangepast. Recent is de Nederlandse Voedsel- en Warenautoriteit (NVWA) geattendeerd dat er een mogelijke verwisseling van forfaitaire waarden van varkensgier mestcode 42 en filtraat, mestcode 41 , heeft plaatsgevonden.

WFSR heeft op verzoek van de NVWA een evaluatie uitgevoerd ter controle of er inderdaad een verwisseling heeft plaats gevonden bij het vaststellen van de forfaitaire waarden van fosfaat in mestcode 41 en 42 en daarnaast een oordeel te geven over de huidige forfaitaire waarden ten opzichte van waarden die in de praktijk worden gemeten.

Op basis van deze evaluatie is geconcludeerd dat er geen verwisseling van de forfaitaire waarde heeft plaatsgevonden bij het vastleggen van de forfaitaire waarden. Naar aanleiding van de vergelijking met de praktijkcijfers wordt aanbevolen de forfaitaire waarde van filtraat van varkensmest na mestscheiding, mestcode 41 , te actualiseren door deze te verlagen naar $0,8 \mathrm{~g} \mathrm{P}_{2} \mathrm{O}_{5} / \mathrm{kg}$. Voor mestcode 42 wordt geen wijziging voorgesteld. 


\section{$1 \quad$ Algemeen}

In Nederland is het verplicht om elke vracht mest die getransporteerd wordt naar een andere bedrijf te laten bemonsteren voor de bepaling van de totaal fosfor (uitgedrukt in $\mathrm{P}_{2} \mathrm{O}_{5}$ ) en stikstofgehalten ( $\mathrm{N}$ ) ter verantwoording van de mestboekhouding. Echter, indien er in dit proces van vastlegging onvolkomenheden optreden, kan er onder voorwaarden gebruik gemaakt worden van forfaitaire fosfaat en stikstofgehalten.

De NVWA is geattendeerd op een mogelijke verwisseling van forfaitaire waarden van fosfaat in varkensgier mestcode (MC) 42 en filtraat na mestscheiding, MC 41 . Deze zijn nu vastgesteld op $1,6 \mathrm{~kg} \mathrm{P}_{2} \mathrm{O}_{5} /$ ton voor $\mathrm{MC} 41$ en $0,9 \mathrm{~kg} \mathrm{P}_{2} \mathrm{O}_{5} /$ ton voor $\mathrm{MC} 42^{1}$.

Deze rapportage beschrijft de evaluatie die door WFSR is uitgevoerd ter controle of er geen verwisseling van de forfaitaire waarden heeft plaatsgevonden bij het vastleggen forfaitaire waarden voor $\mathrm{N}$ en $\mathrm{P}_{2} \mathrm{O}_{5}$ die gehanteerd worden voor $\mathrm{MC} 41$ en 42 . Daarnaast is er een vergelijking gemaakt van de huidige forfaitaire waarden van $\mathrm{P}_{2} \mathrm{O}_{5}$ in $\mathrm{MC} 41$ en 42 ten opzichte van de praktijkgegevens.

Voor de volledigheid wordt hier, nogmaals, gewezen op het slordige taalgebruik in de praktijk van normen voor fosfor. De mestwetgeving spreekt over fosfaat, maar bedoeld wordt totaal fosfor in welke vorm dan ook. Vanuit historische reden worden de fosfornormen uitgedrukt in $\mathrm{P}_{2} \mathrm{O}_{5}$. De lezer wordt gevraagd hier alert op te zijn en bij het overnemen van getalwaarden de eenheid er expliciet bij te zetten. 


\section{Methode}

Voor de evaluatie van het forfait van MC 41 en MC 42 is er een controle uitgevoerd of de huidig geldende forfaitaire waarden bij de vastlegging correct zijn overgenomen uit de literatuur. De forfaitaire waarden voor $\mathrm{P}_{2} \mathrm{O}_{5}$ van MC 41 en 42 zijn in januari 2019 voor het laatst aangepast, hiervoor gold een waarde van 0,6 kg $\mathrm{P}_{2} \mathrm{O}_{5} /$ ton voor $\mathrm{MC} 41$ en 42.

De forfaitaire waarden van $\mathrm{N}$ en $\mathrm{P}_{2} \mathrm{O}_{5}$ in varkensgier, $\mathrm{MC} 42$, zijn vastgesteld op basis van het onderzoek van Commissie Bemesting Grasland en Voedergewassen in 20112. Hierbij is uitgegaan van de waarden voor zeugengier omdat er meer gier van zeugen op de markt zal zijn dan van vleesvarkens.

De forfaitaire waarden van $\mathrm{N}$ en $\mathrm{P}_{2} \mathrm{O}_{5}$ in filtraat na mestscheiding, $\mathrm{MC} 41$, zijn vastgesteld op basis van de technische notitie door Wageningen University \& Research ten behoeve van de evaluatie van de Meststoffenwet in $2016^{3}$. In deze notitie is de verwachte samenstelling voor filtraat van runder- en varkensdrijfmest berekend, uitgaande van het gebruik van een vijzelpers voor runderdrijfmest en een centrifuge voor varkensdrijfmest. Bij deze berekening is uitgegaan van een mestsamenstelling zoals deze in 2013 door het Centraal Bureau voor Statistiek (CBS) is gerapporteerd ${ }^{4}$ en ingeschatte scheidingsefficiënties op basis van praktijkgegevens.

De vergelijking van de huidig geldende forfaitaire waarden van $\mathrm{P}_{2} \mathrm{O}_{5}$ in $\mathrm{MC} 41$ en 42 met actuele praktijkgegevens is uitgevoerd met van de NVWA verkregen vastgestelde gemiddeld gemeten $\mathrm{P}_{2} \mathrm{O}_{5}$ gehalten in deze mestsoorten op basis van het Vervoersbewijs dierlijke mest (VDM) register van Rijksdienst voor Ondernemend Nederland (RVO). Voor stikstof zijn deze cijfers niet beschikbaar gesteld. 


\section{Resultaat \& discussie}

In Tabel 1 staan de forfaitaire waarden voor $\mathrm{N}$ en $\mathrm{P}_{2} \mathrm{O}_{5}$ gehalte in $\mathrm{MC} 41$ en MC 42 weergeven en gemiddelde $\mathrm{P}_{2} \mathrm{O}_{5}$ gehalten die door de NVWA zijn vastgesteld op basis van het VDM register van RVO.

Tabel 1 Het forfaitaire fosfaat en stikstofgehalte voor MC 41 en 42 en het gemiddelde op basis van het VDM register van afgelopen 3 jaar.

\begin{tabular}{lllll} 
Mestcode & Huidig forfait & VDM register (afgelopen 3 jaar) \\
\cline { 2 - 4 } & $\mathrm{N}(\mathrm{g} / \mathrm{kg})$ & $\mathrm{P}_{2} \mathrm{O}_{5}(\mathrm{~g} / \mathrm{kg})$ & $\mathrm{N}(\mathrm{g} / \mathrm{kg})$ & $\mathrm{P}_{2} \mathrm{O}_{5}(\mathrm{~g} / \mathrm{kg})$ \\
\hline 41 (filtraat na mestscheiding, varken) & 6,8 & $1,6 *$ & $0,84 * *$ \\
\hline 42 (varkens gier) & 2,0 & $0,9 *$ & $1,41^{* *}$ \\
\hline
\end{tabular}

*Aangepast per 29-1-2019, hiervoor was het forfait van $\mathrm{P}_{2} \mathrm{O}_{5}$ 0,6 g/kg voor MC 41 en 42 .

**Aangeleverd door de NVWA, vastgesteld op basis van 40.000 VDMs/jaar van MC 41 en 65 VDMs/jaar van MC 42 .

De huidige forfaitaire waarden van $\mathrm{N}$ en $\mathrm{P}_{2} \mathrm{O}_{5}$ gehalten in $\mathrm{MC} 41$ en 42 komen overeen met de waarden uit de gepubliceerde literatuur ${ }^{2,3}$. Er is echter wel een duidelijk verschil tussen de destijds vastgestelde forfaitaire waarden voor $\mathrm{P}_{2} \mathrm{O}_{5}$ en het op basis van het VDM register vastgestelde gemiddelde over de afgelopen 3 jaar.

In de praktijk wordt bij grootschalige verwerking van varkensdrijfmest sinds een paar jaar steeds vaker gebruik gemaakt van een zeefbandpers met vlokmiddelen om de scheidingsefficiëntie van $\mathrm{P}_{2} \mathrm{O}_{5}$ in de dikke fractie te verhogen. Hierdoor blijft er minder $\mathrm{P}_{2} \mathrm{O}_{5}$ achter in het filtraat, $\mathrm{MC} 41$, dat na mestscheiding verkregen wordt. Dit verklaart waarom de gemiddelde concentraties voor $\mathrm{P}_{2} \mathrm{O}_{5}$ in $\mathrm{MC}_{4}$ in het VDM register lager zijn dan in de technische notitie toentertijd is bepaald ${ }^{3}$. 


\section{$4 \quad$ Conclusie en aanbevelingen}

Op basis van deze evaluatie kan geconcludeerd worden dat:

- Er geen verwisseling van de forfaitaire waarde heeft plaatsgevonden bij het vastleggen van de forfaitaire waarden.

- Het overgrote deel van de naar elders afgezette dunne varkensmest vrijkomt als filtraat (MC 41) en maar in een zeer beperkt aantal gevallen als gier (MC 42).

- Dat de op basis van het VDM register bepaalde gemiddelde fosfaatgehalte in MC 41 van de afgelopen 3 jaar lager zijn dan de huidig geldende forfaitaire waarde. Dit is te verklaren doordat het forfait destijds is vastgesteld uitgaande van een centrifuge voor de scheiding van de varkensmest. Terwijl in de praktijk steeds vaker gebruik wordt gemaakt van een zeefbandpers met vlokmiddelen, waardoor er minder fosfaat achterblijft in het filtraat, MC 41, dat na mestscheiding wordt verkregen.

Gelet op de bovenstaande bevindingen wordt de volgende aanbevelingen gedaan:

- Aanpassing van de forfaitaire waarde voor fosfaatgehalte van MC 41, door deze te verlagen van $1,6 \mathrm{~g} \mathrm{P}_{2} \mathrm{O}_{5} / \mathrm{kg}$ naar $0,8 \mathrm{~g} \mathrm{P}_{2} \mathrm{O}_{5} / \mathrm{kg}$.

- Geen wijziging te doen aan de forfaitaire waarde voor $\mathrm{P}_{2} \mathrm{O}_{5}$ in $\mathrm{MC} 42$. 


\section{Literatuur}

1. RVO (2021) Mestbeleid 2019-2021 Tabel 11 Normen en mestcodes aanvoer en afvoer (dierlijke mest. Verkregen van: https://www.rvo.nl/onderwerpen/agrarisch-ondernemen/mest/tabellen

2. Den Boer, D.J. et al. (2012) Mestsamenstelling in Adviesbasis Bemesting Grasland en Voedergewassen. Wageningen UR Livestock Research. Mestsamenstelling in Adviesbasis Bemesting Grasland en Voedergewassen. Verkregen van: https://library.wur.nl/WebQuery/wurpubs/421529

3. Verdoes, N. et al. (2016) Technische notitie betreffende de samenstelling van dierlijke mest na mestscheiding in het kader van Evaluatie van de Meststoffenwet 2016. Wageningen UR.

4. CBS (2013) Dierlijke mest en mineralen 2013.

Verkregen van: https://www.cbs.nl/nl-nl/publicatie/2014/51/mest-en-mineralenproductie-2013 
Wageningen Food Safety Research Postbus 230

6700 AE Wageningen

T 0317480256

www.wur.nl/food-safety-research

WFSR-rapport 2021.016
De missie van Wageningen University \& Research is 'To explore the potential of nature to improve the quality of life'. Binnen Wageningen University \& Research bundelen Wageningen University en gespecialiseerde onderzoeksinstituten van Stichting Wageningen Research hun krachten om bij te dragen aan de oplossing van belangrijke vragen in het domein van gezonde voeding en leefomgeving. Met ongeveer 30 vestigingen, 6.800 medewerkers ( $6.000 \mathrm{fte}$ ) en 12.900 studenten behoort Wageningen University \& Research wereldwijd tot de aansprekende kennisinstellingen binnen haar domein. De integrale benadering van de vraagstukken en de samenwerking tussen verschillende disciplines vormen het hart van de unieke Wageningen aanpak.

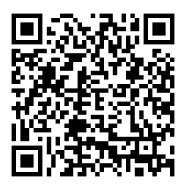





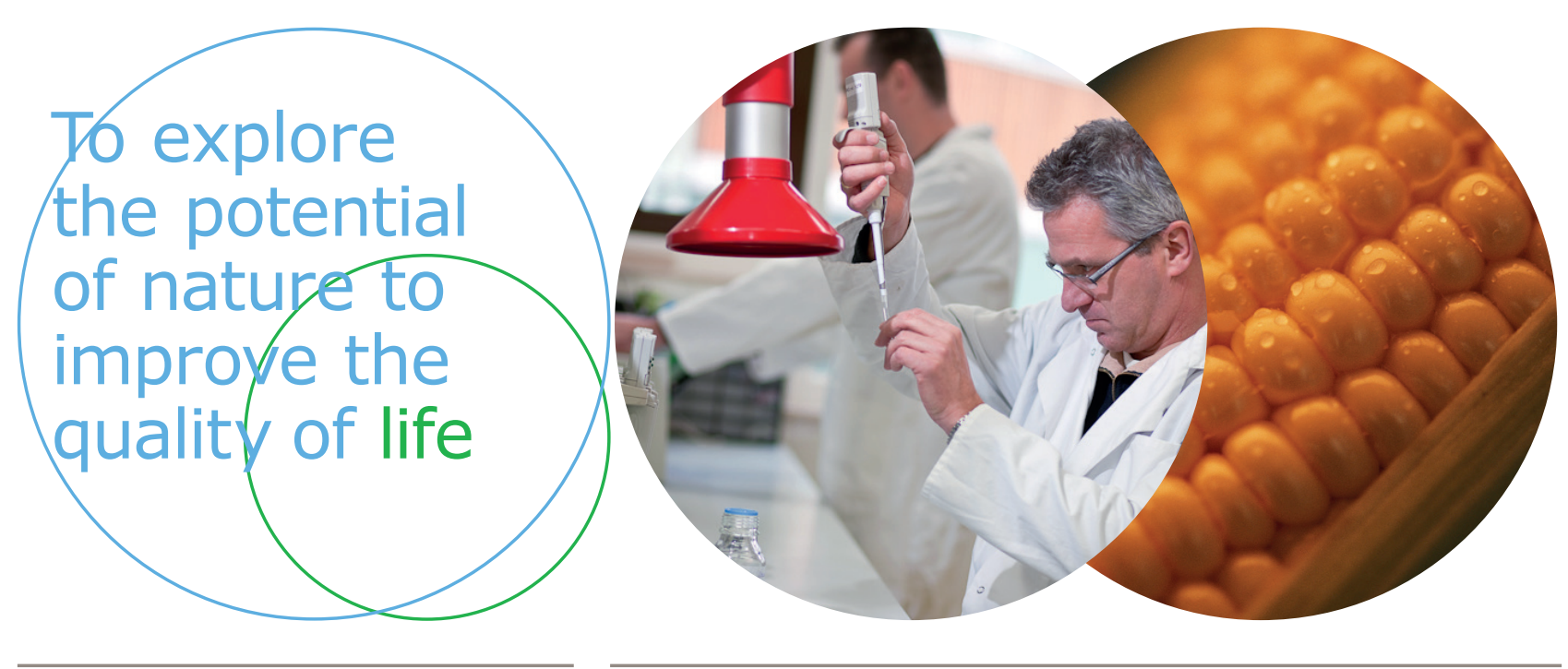

Wageningen Food Safety Research Postbus 230

6700 AE Wageningen

T 0317480256

www.wur.nl/food-safety-research

WFSR-rapport 2021.016
De missie van Wageningen University \& Research is 'To explore the potential of nature to improve the quality of life'. Binnen Wageningen University \& Research bundelen Wageningen University en gespecialiseerde onderzoeksinstituten van Stichting Wageningen Research hun krachten om bij te dragen aan de oplossing van belangrijke vragen in het domein van gezonde voeding en leefomgeving. Met ongeveer 30 vestigingen, 6.800 medewerkers (6.000 fte) en 12.900 studenten behoort Wageningen University \& Research wereldwijd tot de aansprekende kennisinstellingen binnen haar domein. De integrale benadering van de vraagstukken en de samenwerking tussen verschillende disciplines vormen het hart van de unieke Wageningen aanpak. 